\title{
Novel treatments for systemic lupus erythematosus
}

\author{
Wen Xiong and Robert G. Lahita
}

\begin{abstract}
There are many new therapeutic directions for the disease systemic lupus erythematosus (SLE). Despite this, the US Food and Drug Administration (FDA) has approved only one biological agent and it involves $B$ cells, now thought to play a significant role in the pathogenesis of SLE. The name of the drug is belimumab, which is an agent that removes the B-cell cytokine called B lymphocyte stimulation factor (BLyS). Rituximab did not achieve its primary endpoints, even though the consensus is that it may be effective in some forms of SLE including renal disease. The anticytokine therapies against interleukin (IL)-6, IL-10, IL-17 and tumor necrosis factor (TNF) are effective in their own ways and phase II and III trials are in progress. Of particular interest to immunologists are the anti-interferon alpha and gamma drugs, which show promise in the animal models. Modulation of costimulatory molecules; specifically, the anti CD40, CTLA-Ig and ICOS/B7RP blockade agents offer possibilities for the future using new pathways heretofore limited to rheumatoid arthritis. Finally, the use of tyrosine kinase inhibitors is another direction that has been successful in the inhibition of SLE in the murine model; early trials in human SLE have begun.
\end{abstract}

Keywords: lupus, systemic lupus erythematosus, biologics, B cells, anticytokine therapies

\section{Introduction}

Systemic lupus erythematosus (SLE) is a complex multisystem disease for which there is no cure. The use of nontargeted chemotherapeutic agents such as corticosteroids and other cytotoxic agents used in a judicious manner resulted in an overall increase in survival. In the 1950s, about half of the patients with SLE survived 10 years, whereas today that number is over $90 \%$ [Bongu et al. 2002]. Despite this remarkable improvement in survival, the morbidity of the disease continues to be severe in some patients. Moreover, organ system involvement and the heterogeneity of clinical presentation make this a difficult disease both to treat and to diagnose. In fact, it could be said that the lack of acceptable new treatments for lupus is a result of the heterogenic presentation and variability of disease manifestations in different age groups, ethnicities and genders. The agencies that approve drugs for the treatment of lupus have been stymied by various issues: among them, a variety of clinical scales for measuring disease activity, the lack of well established endpoints of improvement, and the overall low numbers of patients with the disease.
In this brief review, we describe a number of new directions in the treatment of lupus using new knowledge within the field of immunology and cell biology. The potential mechanisms of targeted immunotherapy are summarized in Figure 1. These approaches are varied but have a common theme among them, the attenuation of the aberrant immune response that we call autoimmunity.

\section{B-cell-targeted therapies}

Over the years, a variety of cell types has been investigated with regard to the pathogenesis of lupus. Recently, the B cell has taken a place as having a major role in the pathogenesis of SLE [Calero and Sanz, 2010]. In SLE, a large variety of autoantibodies are synthesized and directed against a curious group of relatively conserved antigens such as native DNA, ribonucleoprotein, platelets, and chromatin. The loss of B-cell tolerance is at the heart of these antibodies, although the selection of the antigens remains unknown.

A number of approaches to the control of B cells are possible in the human: B-cell depletion using
Ther Adv Musculoskel Dis (2011) 3(5) 255-266

DOI: $10.1177 /$ $1759720 \times 11415456$

(C) The Author(s), 2011. Reprints and permissions: http://www.sagepub.co.uk/ journalsPermissions.nav

Correspondence to: Robert G. Lahita, MD, PhD Newark Beth Israel Medical Center Medicine, 201 Lyons Avenue, Newark, NJ 07112, USA rlahitaAsbhcs.com Wen Xiong, MD Newark Beth Israel Medical Center Rheumatology, Newark, New Jersey, USA 


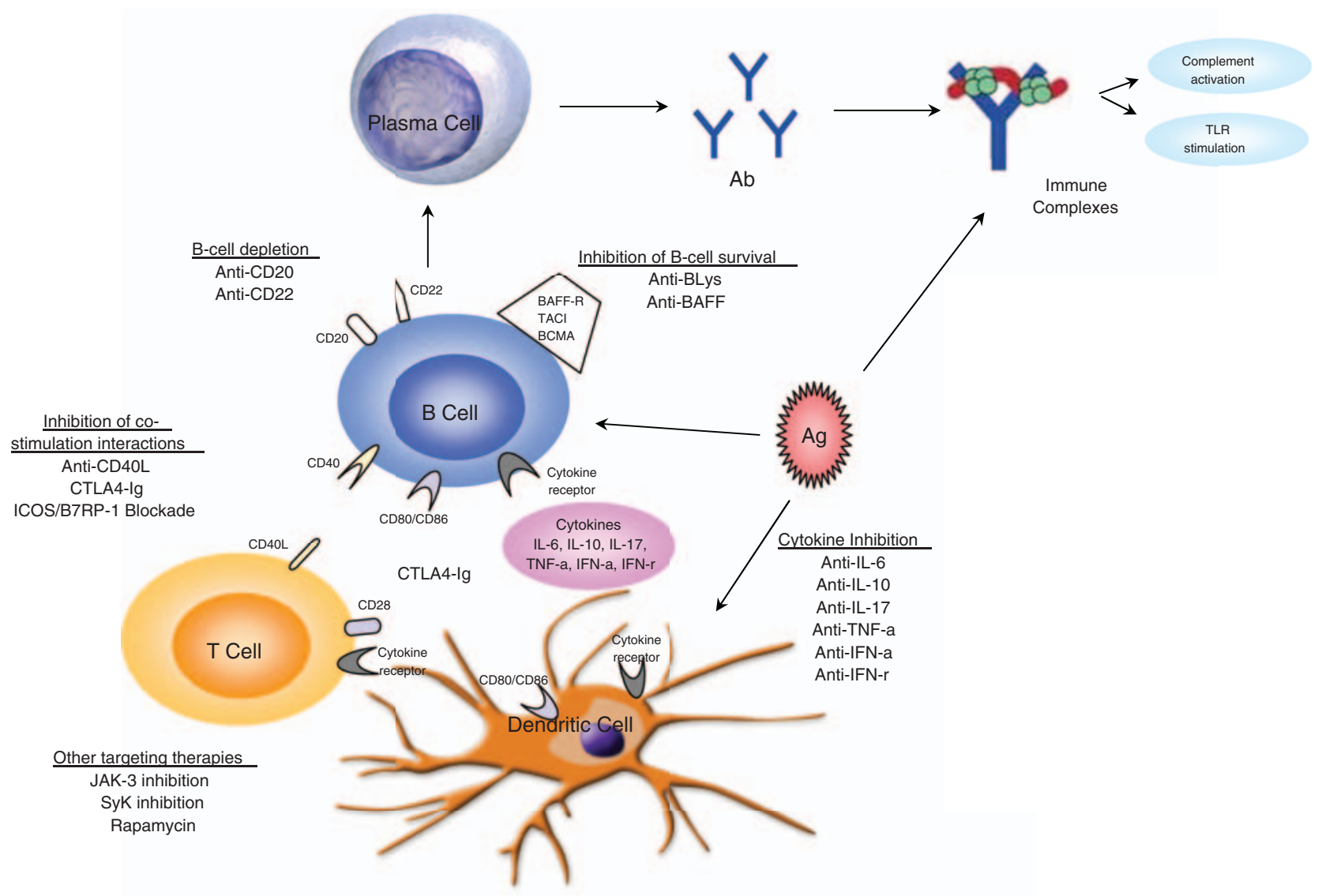

Figure. 1. Mechanism of target biological therapies in SLE. Ag: antigen; Ab: antibody; Anti-IL-6: anti-interleukin-6; Anti-IL-10: antiinterleukin-10; Anti-IL-17: anti-interleukin-17; anti-TNF: anti-tumor necrosis factor; anti-IFN-a: anti-interferon-a; Anti-IFN-r: antiinterferon-r; TLR: toll like receptor; CTLA4-Ig: cytotoxic T lymphocyte activator 4-immunoglobulin; ICOS: Inducible co-stimulator; B7RP-1: B7-related protein-1; BAFF-R: B-cell activating factor; TACl: transmembrane activator and calcium-modulating cyclophilin ligand interactor; BCMA: B cell maturation antigen; SyK: Spleen tyrosine kinase. Adapted by the author and reprinted with permission from Klippel, J. H. et al. Primer on the Rheumatic Diseases. 13th ed. pp. 335.

monoclonal antibodies; inhibition of signals within the B-cell compartment; costimulatory blockade, which involves the insertion of a molecule between the antigen-presenting cell (APC) and the $\mathrm{B}$ cell; and finally cytokine blockade. Cytokine blockade is the mechanism which is the basis for the first new biological agent approved for the treatment of lupus, belimumab.

\section{$B$-cell depletion}

B-cell depletion involves the CD20 targeted antibody known as rituximab. CD20 is a member of a family of membrane proteins expressed on immature, naïve, memory, and germinal center $\mathrm{B}$ cells but not on pre-b or plasma cells [Anolik, 2011]. In vitro rituximab can kill $\mathrm{B}$ cells in a variety of ways. Early murine experiments, many anecdotal cases, and open-label studies suggested that rituximab could be an effective way to control lupus including refractory renal or hematological disease, with or without conventional chemotherapeutic agents such as cyclophosphamide [Conti et al. 2011]. Despite these reports of success, there were two placebo-controlled trials in nonrenal lupus (Explorer) and renal lupus (Lunar) which failed to meet primary endpoints [Merrill et al. 2011; Furie et al. 2009]. Owing to this, the drug was not approved for use in lupus and exemplified the problems associated with organ-specific clinical trials, design and measurement of outcome in this particularly vexing illness [Hahn, 2011].

Another B-cell-depleting drug that has potential is epratuzumab, a humanized anti-CD22 that also induces $\mathrm{B}$-cell depletion although the depletion is less (involving only $25-40 \%$ of $\mathrm{B}$ cells). The activation and stimulation of these $\mathrm{B}$ cells is also inhibited suggesting that the drug may also act as a regulator of B-cell function [La Cava, 2010]. The EMBLEM 
trial is a multicenter, randomized, double-blind, phase IIb study, which was designed to assess the efficacy and safety of epratuzumab in patients with moderate-to-severe SLE. The study demonstrated clinically meaningful improvements in disease activity measured by BILAG scores in 227 patients. [Wallace et al. 2010] Other agents include a humanized monoclonal antibody against CD20, ocrelizumab, which depletes B cells from the peripheral circulation but allows their regeneration from hematopoietic stem cells. Two phase III trials known as BELONG and BEGIN assessed the efficacy and safety of ocrelizumab in SLE patients with or without active glomerulonephritis. Both trials are not recruiting participants, and no results are yet available [ClinicalTrials.gov identifiers NCT00626197 and NCT00539838].

\section{$B$-cell stimulation inhibition}

The development of anticytokine drugs in lupus resulted in a new drug called belimumab $\left(\right.$ Benlysta $^{\circledR}$ ) [Morrow, 2011]. This is a fully human monoclonal antibody against B-lymphocyte stimulator (BLyS). This cytokine (also called BAFF, TALL-1, and zTNF4) is a member of the tumor necrosis factor alpha (TNF- $\alpha$ ) super family and plays an important role in B-cell proliferation and antibody production. A related cytokine is APRIL (a proliferation-inducing ligand). All are important cytokines for the overall survival and well-being of B cells [Ota et al. 2010]. Early data in lupus patients suggested that BLyS is elevated in SLE, Sjögren's syndrome and rheumatoid arthritis (RA) patients and blockade of this cytokine had beneficial effects in lupus animal models [Vadacca et al. 2010]. There were some initial problems with the early clinical trials in which the primary efficacy endpoint was not met. Later in phase II trials at both 52 and 76 weeks, patients treated with belimumab had less flares and decreased clinical activity than patients treated with placebo [Wiglesworth et al. 2010]. There were no significant adverse effects noted with belimumab. In subgroup analysis, patients who were seropositive had a better response than those who were seronegative. It is known that anti-dsDNA titers and other autoantibodies decrease when belimumab is given. Moreover, only about $25 \%$ of patients have elevated levels of BLyS at any one time and these titers vary with clinical activity. As a final note, there was some early concern about the lack of efficacy in the African American populations due to the differences in the ethnicity of the patients studied.
There are other cytokine inhibitors for lupus that are in development and these include atacicept, which is a fusion protein composed of the extracellular domain of one of the BAFF receptors called TACI (transmembrane activator and calcium modulator and cyclophilin ligand interactor). A phase II study of atacicept given with mycophenolate mofetil in patients with lupus nephritis was terminated because of severe infections [ClinicalTrials.gov identifier: NCT00573157]. Currently, a phase II/ III, randomized, controlled trial of atacicept for nonrenal lupus patients that involves less immunosuppressive concomitant therapy is ongoing [ClinicalTrials.gov identifier: NCT00624338].

\section{Anticytokine therapies}

\section{Anti-IL-6 antibody}

Interleukin-6 (IL-6) is a key proinflammatory cytokine. In murine models of lupus, an age-associated increase in serum levels of IL- 6 and abnormal expression of the IL-6 receptor have been described [Suzuki et al. 1993]. IL-6 increases autoantibody production and accelerates the progression of glomerulonephritis [Ryffel et al. 1994]. Blockade of IL-6 or its receptor leads to a significant decrease in the spontaneous production of immunoglobulin and anti-dsDNA antibodies and prevents the progression of proteinuria [Liang et al. 2006]. Elevated serum levels of IL-6 were found in patients with SLE, and correlated with disease activity or anti-dsDNA levels [Chun et al. 2007]. Moreover, studies showed urinary excretion of IL- 6 was increased in patients with active proliferative lupus nephritis [Tsai et al. 2000].

Tocilizumab, a humanized monoclonal antibody against the $\alpha$-chain of the IL- 6 receptor, prevents the binding of IL- 6 to membrane-bound and soluble IL-6 receptor. The efficacy and safety of tocilizumab have been evaluated in clinical trials in patients with RA, juvenile idiopathic arthritis (JIA), and Castleman's disease [Straub et al. 2006]. Currently, it is approved for management of RA and JIA.

Illei and colleagues performed an open-label phase I dose-escalation study of tocilizumab in 16 patients with mild to moderate SLE. After subjects received tocilizumab in one of three doses $(2,4$, or $8 \mathrm{mg} / \mathrm{kg}$ ) twice weekly for 12 weeks, the SLE disease activity (SELENASLEDAI) score decreased significantly. Inflammatory marker and levels of autoantibodies were also reduced. Almost all subjects, however, developed dose-related neutropenia and 
high rates of infections were reported, which may limit the maximum dosage of tocilizumab in patients with SLE. Further studies to establish the optimal dosing regimen and efficacy of tocilizumab are warranted [Illei et al. 2010].

\section{Anti-IL-10 antibody}

IL-10 is an inhibitory cytokine for T cells which suppresses the activity of other proinflammatory cytokines such as interferon gamma (IFN- $\gamma$ ), TNF- $\alpha$ and granulocyte macrophage colony-stimulating factor (GM-CSF). However, IL-10 has properties that are somewhat ambivalent. Lupus patients with pulmonary involvement have a higher proinflammatory cytokine profile including IL-6, IL-8, IL-10, IL-12, IFN- $\gamma$ and TNF- $\alpha$, suggesting the involvement of IL-10 in many facets of development and prognosis of SLE [Al-Mutairi et al. 2007]. B-cell secretion of IL10 regulates dendritic cell and T-cell function, promoting type-2 $\mathrm{T}$ helper cell (Th2) deviation of the immune response. In turn, IL-10 contributes to a number of the earlier described peripheral B-cell abnormalities in SLE, including plasma cell expansion [Jacobi et al. 2003].

Data regarding the role of IL-10 in a lupus-like animal model and in human SLE are controversial. IL-10-deficient MRL-Fas 1pr mice have had an increased type-1 $\mathrm{T}$ helper cell (Th1) response and autoantibody production when compared with IL $-10+/+$ mice. These data suggested that IL-10 may downregulate autoantibody production and end-organ damage through inhibition of Th1 cytokine production [Yin et al. 2002]. Another study reported continuous administration of anti-IL-10 antibody in New Zealand black and white $\mathrm{F} 1$ hybrid (NZB/W F1) mice had a protective effect in proteinuria and glomerulonephritis and produced delayed onset of autoimmunity. It is interesting that the protective effect of anti-IL10 antibodies was abolished by the concomitant administration of blocking anti-TNF antibodies, suggesting that an immunoregulatory balance exists between these two cytokines in the NZB/ W mouse [Ishida et al. 1994].

IL-10 levels are elevated in the sera of SLE patients and correlate with clinical and serological changes [Houssiau et al. 1995]. A small openlabel trial of anti-IL-10 monoclonal antibody involved six subjects who received $20 \mathrm{mg}$ of anti-IL-10 antibody intravenously for 21 days. In these patients, the SLE Disease Activity Index (SLEDAI) score decreased significantly by day 21 and was maintained for 6 months. Skin and joint symptoms improved in all patients. Prednisolone dose also decreased significantly over the 6-month period [Llorente et al. 2000].

\section{Anti-IL-17 antibodies}

IL-17 is an important proinflammatory cytokine of the adaptive immune system, which is produced primarily by the $\mathrm{T}$ helper 17 (TH17) subset of T cells. Studies have shown that IL17 and TH17 cells are central to the development and pathogenesis of autoimmune diseases including RA and animal models of autoimmunity [Yoo, 2010]. There is a relationship between SLE and IL-17/TH17 cells. Serum levels of IL17 and the TH17 cell fraction are increased in patients with SLE [Wong et al. 2008]. IL-17 increases autoantibody production in patients with lupus nephritis from peripheral blood mononuclear cells (PBMCs) [Dong et al. 2003].

Two humanized anti-17 monoclonal antibodies have been developed and evaluated in clinical trials for the treatment of rheumatoid arthritis, psoriasis and chronic uveitis. Eli Lilly and Company (Indianapolis, Indiana, USA) developed LY2439821, a humanized anti-IL-17 monoclonal antibody. The safety, tolerability, and efficacy of LY2439821 were assessed in a phase I randomized, double-blind, placebo-controlled study. It showed significant promise in RA patients taking oral disease-modifying antirheumatic drugs (DMARDs). There was no strong adverse safety signal noted. LY2439821 added to oral DMARDs improved the signs and symptoms of RA compared with placebo-treated patients [Genovese et al. 2010]. The phase II study of LY2439821 (an anti-IL-17 antibody) in patients with active rheumatoid arthritis is ongoing [ClinicalTrials.gov identifier: NCT00966875].

Another humanized anti-17 monoclonal antibody, AIN457, developed by Novartis (Basel, Switzerland), shows safety and efficacy in patients with psoriasis, RA, and uveitis [Hueber et al. 2010]. AIN457 treatment showed variable responses in patients suffering from each of these diseases. These studies supported a role for IL-17 in the pathophysiology of diverse inflammatorymediated diseases, and its potential role in the treatment of SLE needs to be carefully examined.

Anti-TNF- $\alpha$ agents

$\mathrm{TNF}-\alpha$ is a proinflammatory as well as regulatory cytokine with divergent effects on the immune 
system in SLE. TNF- $\alpha$ promotes apoptosis and significantly affects the activity of $\mathrm{B}$ cells, $\mathrm{T}$ cells, and dendritic cells (DCs). In different strains of lupus mice, the expression of $\mathrm{TNF}-\alpha$ has beneficial effects on the disease but $T N F-\alpha$ therapy is highly detrimental in other murine models [Edwards et al. 1996; Brennan et al. 1989]. In kidney inflammation, the renal expression of TNF- $\alpha$ is usually increased. Sera and inflamed kidney tissue samples from MRL/lpr lupus mice contain significant amounts of $\mathrm{TNF}-\alpha$ associated with disease activity [Theofilopoulos and Lawson, 1999]. In humans, TNF- $\alpha$ concentrations are actually increased in sera of SLE patients and closely associated with disease activity. As both soluble $\mathrm{TNF}-\alpha$ receptors are likewise increased and correlate with disease activity, it was thought that they would block the biological activity of the increased serum TNF. There could be a relative lack of $\mathrm{TNF}-\alpha$ with reduction in the ratio of $\mathrm{TNF}-\alpha$ to soluble $\mathrm{TNF}-\alpha$ receptors. Moreover, $\mathrm{TNF}-\alpha$ was found in the inflamed kidneys of patients with lupus glomerulonephritis and correlated with histological disease activity [Aringer and Smolen, 2005]. These findings, therefore, argue for a pathogenic role of $\mathrm{TNF}-\alpha$ in the local inflammatory disease processes in SLE.

The effect of anti-TNF- $\alpha$ therapy in SLE patients has been demonstrated in small studies. Aringer and colleagues performed a small, open-label pioneer study that demonstrated a decrease in disease activity in six SLE patients treated with infliximab plus azathioprine or methotrexate, although the levels of anti-dsDNA antibodies and anticardiolipin increased in four out of six patients. There were three urinary tract infections, one Escherichia coli bacteremia, and one prolonged suspected viral fever [Aringer et al. 2004]. Later, a follow-up study showed an increase in antibody against DNA, histone, chromatin, and cardiolipin IgM despite an overall reduction in disease activity [Aringer et al. 2007]. Recently, their experiences with a total of 13 lupus nephritis patients showed that short-term induction therapy at a dose of $5 \mathrm{mg}$ / $\mathrm{kg}$ of infliximab was relatively safe, and was effective for years without flare up in lupus nephritis. However, long-term infusion was associated with severe adverse events, for example central nervous system (CNS) lymphoma and Legionella pneumonia in two out of three SLE patients [Aringer et al. 2009].
There are two pilot studies conducted in Asia with reduced infliximab dosage. Nine Japanese patients with refractory lupus nephritis received $200 \mathrm{mg}$ of infliximab on three occasions. One subject dropped out of the study because of pyelonephritis after the first infusion. Proteinuria and disease activity of SLE improved significantly in six out of eight subjects [Matsumura et al. 2009]. In a Kuwaiti pilot study, nine SLE patients received five infusions of infliximab at $3 \mathrm{mg} / \mathrm{kg}$ of body weight, and showed significant improvement in disease activity compared with 18 patients who received standard care [Uppal et al. 2009]. No safety issues were reported except for infusion reactions in four patients.

Two large randomized trials were designed to evaluate the efficacy and safety of TNF- $\alpha$ inhibitors (infliximab, etanercept) in active lupus nephritis, but both were terminated prematurely. [ClinicalTrials.gov identifiers: NCT00368264 and NCT00447265] In addition, a phase II open-label study to assess the efficacy and safety of etanercept for the treatment of discoid lupus erythematosus is ongoing [ClinicalTrials.gov identifier: NCT00797784].

The safety of anti-TNF- $\alpha$ therapy in RA patients has been addressed in several large national registries and meta-analysis studies [Leombruno et al. 2009; Bongartz et al. 2006; Dixon et al. 2006]. Anti-TNF- $\alpha$ treatment given to patients with RA is associated with increased risk of skin and soft tissue infection, intracellular bacterial infection, skin cancer, and lymphoma, as well as the development of antibodies to dsDNA, chromatin, or phospholipid. A minority of patients may develop clinical mild lupus, but not with major organ involvement. Recently, six cases of severe SLE have been reported after the use of anti-TNF- $\alpha$ for the treatment of inflammatory arthritis [Soforo et al. 2010].

In view of the above findings, anti-TNF- $\alpha$ therapy currently is not recommended to be used routinely for patients with SLE.

\section{Anti-IFN- $\alpha$ therapy}

The most prominent immunopathogenetic feature in SLE patients is an increased expression of type I IFN-regulated genes (IFN signature) in PBMCs and tissues such as the kidney [Rönnblom et al. 2009]. Activated plasmacytoid dendritic cells (pDCs) synthesize the majority of 
IFN- $\alpha$ and can be found in target organs. Excessive production of IFN- $\alpha$ leads to breakdown of peripheral tolerance via its action on cells of innate an adaptive immunity (DCs, $\mathrm{T}$ and $\mathrm{B}$ cells). Results from an experimental lupus model suggest that IFN- $\alpha$ actually drives the nephritis and end-organ damage [Fairhurst et al. 2008]. Moreover, type I IFNAR knockout experimental murine lupus models have markedly reduced disease activity [SantiagoRaber et al. 2003]. Patients with SLE have increased serum levels of IFN- $\alpha$, which correlate to both disease activity and severity. In addition, several clinical manifestations, such as skin rash, fever and leucopenia, as well as several markers of immune activation correlate with serum IFN- $\alpha$ levels [Bengtsson et al. 2000].

The role of type I IFN in the pathogenesis of human SLE suggested that downregulation of this system could be a therapeutic approach. The prime therapeutic target was IFN- $\alpha$ and neutralizing monoclonal antibodies were developed and tested. Wallace and colleagues reported on a phase I clinical trial that showed reduced clinical activity among SLE patients treated with a single injection of an anti-IFN- $\alpha$ monoclonal antibody MEDI-545. There was also dosedependent inhibition of type I IFN-inducible genes in both peripheral blood and skin biopsies. No safety problems reported during this shortterm study [Wallace et al. 2007]. Recently, Yao and colleagues reported on another phase I doseescalation study evaluated the effects of a single dose of anti-IFN monoclonal antibody therapy in SLE [Yao et al. 2009]. The study also showed dose-dependent inhibition of overexpression of IFN- $\alpha / \beta$-inducible genes in peripheral blood and skin biopsies from SLE patients, as well as a reduction in clinical disease activity. In addition, beneficial effects on downstream signaling pathways (BAFF, TNF- $\alpha$, IL-10, IL- 1 , and GMCSF) were reported, and type I INF-inducible mRNA may be a useful biomarker monitoring patient responses after administration of antiIFN $-\alpha$ antibody.

Currently, several large phase II trials are ongoing to evaluate the effects of anti-IFN- $\alpha$ monoclonal antibody in SLE. One of them is a phase II, multicenter, open-label, dose-escalation study to evaluate safety and tolerability of MEDI-545, a fully human anti-IFN- $\alpha$ monoclonal antibody, sifalimumab, in Japanese adult SLE patients. This will be done by collecting the data from three cohorts of intravenous (IV) doses and one cohort of subcutaneous (SC) doses [ClinicalTrials.gov identifier: NCT01031836]. Another phase IIA, multicenter, randomized, double-blind, placebo-controlled, parallel-dose study of subcutaneous doses of MEDI-545 has been completed. Approximate 80 subjects with moderately to severely active SLE were enrolled in the study. No study result has been published [ClinicalTrials.gov identifier: NCT00657189]. There is another ongoing phase II study, the ROSE study, a randomized, double-blind, placebo-controlled multicenter study to evaluate the efficacy and safety of a recombinant human anti-IFN- $\alpha$ monoclonal antibody, rontalizumab, compared with placebo in patients with moderately to severely active SLE. The study enrolled 237 patients at up to 100 sites in North America, Latin America, and Europe [ClinicalTrials.gov identifier: NCT00962832].

\section{Anti-IFN- $\gamma$ therapy}

IFN- $\gamma$, classified as a type II IFN that is mainly produced by Th1-type $\mathrm{T}$ cells and natural killer (NK) cells. Not only does the type I IFN signature contribute an important feature in human SLE, the expression of IFN- $\gamma$ has also been demonstrated as an association with the immunopathogenesis in human and murine SLE. The deletion of the IFN- $\gamma$ receptor gene in both (NZB $x$ NZW) F1 and MRL/Fas lpr mice resulted in the improvement of renal disease and increased survival [Haas et al. 1998]. The administration of IFN- $\gamma$ R-Ig fusion protein to MRL/Fas lpr mice significantly decreased the concentration of IFN- $\gamma$ in plasma and demonstrated therapeutic benefits, including the reduction of autoantibodies and lymphadenopathy, as well as an improvement of renal disease and survival rate [Lawson et al. 2000]. In human SLE, excessive production of IFN- $\gamma$ induced BLyS/ BAFF production by monocytes was reported [Harigai et al. 2008]. In addition, increased levels of IFN- $\gamma$ correlating with disease activity was demonstrated in serum or tissue such as the kidney from SLE patients [Uhm et al. 2003].

AMG 811, a fully human anti-IFN- $\gamma$ monoclonal antibody, is involved in a phase $\mathrm{Ib}$, randomized, multicenter, dose-escalation study in approximately 40 SLE subjects with and without glomerulonephritis. The purpose of the study is to evaluate the multiple dose of AMG 811 on safety, tolerability and pharmacokinetics [ClinicalTrials.gov identifier: NCT00818948]. 


\section{Modulation of costimulatory molecules}

Costimulation plays an important role in the activation $\mathrm{T}$ cells and the development of $\mathrm{T}$ celldependent $\mathrm{B}$ cell responses. Communication between $\mathrm{B}$ cells, other APCs and T cells requires costimulatory signals such as CD40/CD40L, CD28 and cytotoxic T-lymphocyte antigen4 (CTLA4), and CD80 (B7.1)/CD86 (B7.2). Direct inhibition of $\mathrm{B}-\mathrm{T}-\mathrm{cell}$ collaboration via blockade of the CD40/CD40L pathway has been effective in mouse models of lupus [Wang et al. 2003].

\section{Anti-CD40L antibodies}

Two studies of anti-CD40L antibodies in SLE patients have been reported. One open-label study of CD40L antibody treatment in 28 patients with biopsy-proven proliferative lupus nephritis was stopped prematurely due to thromboembolic events, although a significant decrease in proteinuria occurred in two patients [Boumpas et al. 2003].

Another randomized, phase II, double-blinded controlled trial of a different anti-CD40L monoclonal antibody, no significant differences in the SLEDAI or adverse events between placebo and treatment groups were reported [Kalunian et al. 2002].

\section{CTLA-Ig}

An alternative costimulatory target in SLE includes CD28 and CTLA4 receptors, which both bind to CD80 (B7.1)/CD86 (B7.2) receptors on the surface of APCs such as B cells and DCs. Abatacept is a recombinant molecule consisting of the extracellular domain of CTLA and constant region of $\mathrm{Ig}$, which specifically blocks the interactions between CD28 and CD 80(B7.1)/CD86 (B7.2) receptors on APCs [Mihara et al. 2000]. The established safety and efficacy in human RA trails led to its approval by the US Food and Drug Administration (FDA) for the treatment of RA [Kremer et al. 2003].

Currently, there is an ongoing, phase II/III, multicenter, randomized, double-blind, placebo-controlled study, evaluating the efficacy and safety of abatacept on a background of mycophenolate mofetil and corticosteroids in subjects with active proliferative glomerulonephritis [ClinicalTrials.gov identifier: NCT00430677].
ICOS/B7RP-1 blockade

Inducible costimulator (ICOS) is the third member of the CD28/CTLA4 family and is involved in the proliferation and activation of $\mathrm{T}$ cells. It is a membrane glycoprotein that is expressed on the surface of activated $\mathrm{T}$ cells, sharing several structural and functional similarities with CD28. Like CD28, ICOS has potent costimulatory effects on proliferation of $\mathrm{T}$ cells and production of cytokines [McAdam et al. 2000]. ICOS is also important for germinal center formation, clonal expansion of $\mathrm{T}$ cells, antibody production, and class switching in response to various antigens [Yoshinaga et al. 2000]. A B7-like molecule, termed B7-related protein-1 (B7RP-1), binds to ICOS and is constitutively expressed on B cells and monocytes.

Evidence indicates that ICOS is involved in the immunopathogenesis of animal models of various autoimmune disorders, including SLE, RA, multiple sclerosis, and asthma [Iwai, 2003; Nurieva et al. 2003; Wiley et al. 2003; Rottman et al. 2001]. Expression of ICOS on T cells was enhanced with disease progression of lupus in $\mathrm{NZB} / \mathrm{W}$ F1 mice. Administration of anti-B7RP$1 \mathrm{mAb}$ before the onset of renal disease significantly delayed the onset of proteinuria and prolonged survival. In human SLE, ICOS was overexpressed in peripheral blood $\mathrm{CD} 4+\mathrm{T}$ cells from active SLE patients. ICOS contributed not only to the enhanced proliferation but also to the increased production of IFN- $\gamma$ in peripheral blood $\mathrm{T}$ cells from SLE patients. Moreover, ICOS augmented the ability of peripheral blood $\mathrm{T}$ cells to support the production of IgG antidsDNA antibody by autologous peripheral blood B cells [Kawamoto et al. 2006]. These data suggest that ICOS plays an important role in the immunopathogenesis of SLE, and blockade of the interaction between ICOS and B7RP-1 may have therapeutic value in the treatment of SLE.

\section{Other potential targeting therapies}

\section{JAK-3 inhibition}

As common signaling pathways have recently emerged that mediate both T- and B-lymphocyte signaling defects, key regulatory nodes of those pathways may represent optimal pharmaceutical targets in SLE. Among various signaling molecules activated by cytokine-receptor interaction, the small molecule targeting JAK-STAT pathway is an attractive candidate. JAK-3 is critical for 
signal transduction for IL-2, IL-4, IL-7, IL-9, IL15, and IL-21, and selective inhibition of JAK-3 has the potential to mediate potent immune modulation, affecting $\mathrm{T}$ lymphocytes, $\mathrm{B}$ lymphocytes, macrophages, and NK cells, without significantly affecting other organ systems [Kawamura et al. 1994]. CP-690,550 is an orally available JAK, highly selective inhibitor of the JAK-3 antagonist developed for the treatment of RA and other autoimmune conditions, as well as for the prevention of renal allograft rejection. A phase IIa, double-blind, placebo-controlled study trial evaluated the efficacy, safety, and tolerability of three different dosages of CP-690,550 in patients with active RA. The study showed a rapid, statistically significant, and clinically meaningful improvement in the signs and symptoms of RA [Kremer et al. 2009]. These data suggest a specific JAK-3 inhibitor may provide a potential therapeutic option for the treatment of SLE.

\section{Rapamycin}

Activation of the mammalian target of rapamycin, mTOR plays a pivotal role in abnormal activation of $T$ and $B$ cells in SLE. $m$ TOR has multiple regulatory functions in $\mathrm{T}$ - and $\mathrm{B}$-cell intracellular signaling. It controls the expression T-cell receptor-associated signaling proteins through increased expression of the endosome recycling regulator genes, mediates enhanced calcium fluxing and skews the expression of tyrosine kinases both in $\mathrm{T}$ and $\mathrm{B}$ cells, and blocks the expansion of regulatory $\mathrm{T}$ cells [Perl et al. 2009]. Rapamycin (sirolimus) interacts with mTOR by influencing gene transcription and multiple metabolic pathways. In lupus-prone MRL/lpr mice, rapamycin has been shown to prevent the typical rise in anti-dsDNA antibody and urinary albumin levels and glomerulonephritis, and prolong survival [Chen and Fang, 2002]. Rapamycin has been used safely and effectively to treat renal transplant rejection since 1999. Fernandez and colleagues reported a small pilot study that showed efficacy and safety of rapamycin among nine refractory SLE patients [Fernandez et al. 2006]. A phase II, prospective study is ongoing to determine the therapeutic efficacy and mechanism of action of rapamycin in patients with SLE [ClinicalTrials.gov identifier: NCT00779194].

\section{SyK inhibition}

Spleen tyrosine kinase (Syk) is a member of the Src family of nonreceptor tyrosine kinases, involved in membrane-mediated signaling in various cells, including $\mathrm{T}$ and $\mathrm{B}$ cells. Higher amounts of Syk expression and activity were detected in $T$ cells of SLE patients compared with normal $\mathrm{T}$ cells. Selective inhibition of the activity of Syk reversed aberrant T-cell signaling in SLE patients [Krishnan et al. 2008]. R788, an orally bioavailable Syk inhibitor, delayed the development of renal disease and significantly prolonged survival of lupus-prone NZB/NZW mice [Bahjat et al. 2008]. In addition, R788 treatment suppressed established skin and renal disease in the MRL/lpr mice [Deng et al. 2010]. Interestingly, Syk inhibition did not lead to significant inhibition of the production of antidsDNA in both NZB/NZW mice and MRL/lpr mice, whereas it dose-dependently reduced the numbers of $\mathrm{CD} 4+$ activated $\mathrm{T}$ cells. These observations indicate that the clinical effect of SyK inhibition does not rely on the production of antibody, but rather on events downstream of immune complex deposition.

Syk inhibition produced significant clinical benefits in active RA patients from a phase II, randomized, multicenter, placebo-controlled trial [Weinblatt et al. 2008]. Clinical benefit has also been reported in patients with immune thrombocytopenic purpura (ITP) [Bussel et al. 2007]. These preclinical studies reported previously, as well as clinical efficacy of phase II studies in RA and ITP, make a compelling case for exploration of SyK inhibitors in the treatment for SLE patients.

\section{Conclusion}

There have been significant advances in the treatment of SLE, and experts see great promise in Bcell-targeted therapy, especially belimumab. In addition, anticytokine therapies against IL-6, INF- $\alpha$, and INF- $\gamma$, as well as tyrosine kinase inhibitor have offered possibilities for the future using new pathways for the treatment of lupus.

\section{Funding}

This research received no specific grant from any funding agency in the public, commercial, or notfor-profit sectors.

\section{Conflict of interest statement}

The authors declare no conflicts of interest in preparing this article. 


\section{References}

Al-Mutairi, S., Al-Awadhi, A., Raghupathy, R., Al-Khawari, H., Sada, P., Al-Herz, A. et al. (2007) Lupus patients with pulmonary involvement have a proinflammatory cytokines profile. Rheumatol Int 27: 621-630.

Anolik, J. (2011) Immunologic reconstitution after rituximab in systemic lupus erythematosus: why should we care? F Rheumatol 38: 587-589.

Aringer, M., Graninger, W.B., Steiner, G. and Smolen, J.S. (2004) Safety and efficacy of tumor necrosis factor alpha blockade in systemic lupus erythematosus: an open-label study. Arthritis Rheum 50: 3161-3169.

Aringer, M., Houssiau, F., Gordon, C., Graninger, W.B., Voll, R.E., Rath, E. et al. (2009) Adverse events and efficacy of TNF-alpha blockade with infliximab in patients with systemic lupus erythematosus: long-term follow-up of 13 patients. Rheumatology (Oxford) 48: 1451-1454.

Aringer, M. and Smolen, J.S. (2005) Cytokine expression in lupus kidneys. Lupus 14: 189-191.

Aringer, M., Steiner, G., Graninger, W.B., Höfler, E., Steiner, C.W. and Smolen, J.S. (2007) Effect of shortterm infliximab therapy on autoantibodies in systemic lupus erythematosus. Arthritis Rheum 56: 274-279.

Bahjat, F.R., Pine, P.R., Reitsma, A., Cassafer, G., Baluom, M., Grillo, S. et al. (2008) An orally bioavailable spleen tyrosine kinase inhibitor delays disease progression and prolongs survival in murine lupus. Arthritis Rheum 58: 1433-1444.

Bengtsson, A., Sturfelt, G., Truedsson, L., Blomberg, J., Alm, G., Vallin, H. et al. (2000) Activation of type I interferon system in systemic lupus erythematosus correlates with disease activity but not with antiretroviral antibodies. Lupus 9: 664-671.

Bongartz, T., Sutton, A.J., Sweeting, M.J., Buchan, I., Matteson, E.L. and Montori, V. (2006) Anti-TNF antibody therapy in rheumatoid arthritis and the risk of serious infections and malignancies: systematic review and meta-analysis of rare harmful effects in randomized controlled trials. F Am Med Assoc 295: 2275-2285, Erratum f AM Med Assoc 295: 2482.

Bongu, A., Chang, E. and Ramsey-Goldman, R. (2002) Can morbidity and mortality of SLE be improved? Best Pract Res Clin Rheumatol 16: 313-332.

Boumpas, D.T., Furie, R., Manzi, S., Illei, G.G., Wallace, D.J., Balow, J.E. et al. (2003) A short course of BG9588 (anti-CD40 ligand antibody) improves serologic activity and decreases hematuria in patients with proliferative lupus glomerulonephritis. Arthritis Rheum 48: 719-727.

Brennan, D., Yui, M., Wuthrich, R. and Kelley, V. (1989) Tumor necrosis factor and IL-1 in New Zealand Black/White mice. Enhanced gene expression and acceleration of renal injury. $\mathcal{F}$ Immunol 143: 3470-3475.

Bussel, J.B., Schindler, A.M. and Grossbard, E.B. (2007) R935788: a phase II, single center, open label, efficacy and safety, ascending dose, pilot study for the treatment of adult immune thrombocytopenic purpura (ITP) [abstract]. Blood 110: 1310.

Calero, I. and Sanz, I. (2010) Targeting B cells for the treatment of SLE: the beginning of the end or the end of the beginning? Discov Med 10: 416-424.

Chen, J. and Fang, Y. (2002) A novel pathway regulating the mammalian target of rapamycin (mTOR) signaling. Biochem Pharmacol 64: 1071-1077.

Chun, H.Y., Chung, J.W., Kim, H.A., Yun, J.M., Jeon, J.Y., Ye, Y.M. et al. (2007) Cytokine IL-6 and IL-10 as biomarkers in systemic lupus erythematosus. $\mathcal{F}$ Clin Immunol 27: 461-466.

Conti, F., Ceccarelli, F., Perricone, C., Alessandri, C., Conti, V., Massaro, L. et al. (2011) Rituximab infusionrelated adverse event rates are lower in patients with systemic lupus erythematosus than in those with rheumatoid arthritis. Rheumatology (Oxford), [ePub ahead of print].

Deng, G., Liu, L., Bahjat, F.R., Pine, P.R. and Tsokos, G.C. (2010) Suppression of skin and kidney disease by inhibition of spleen tyrosine kinase in lupus-prone mice. Arthritis Rheum 62: 2086-2092.

Dixon, W.G., Watson, K., Lunt, M., Hyrich, K.L., Silman, A.J. and Symmons, D.P. (2006) British Society for Rheumatology Biologics Register Rates of serious infection, including site-specific and bacterial intracellular infection, in rheumatoid arthritis patients receiving anti-tumor necrosis factor therapy: result from the British Society for Rheumatology Biologics Register. Arthritis Rheum 54: 2368-2376.

Dong, G., Ye, R., Shi, W., Liu, S., Wang, T., Yang, X. et al. (2003) IL-17 induces autoantibody overproduction and peripheral blood mononuclear cell overexpression of IL-6 in lupus nephritis patients. Chin Med $\mathcal{F}$ 116: 543-548.

Edwards, C.K., Zhou, T., Zhang, J., Baker, T.J., De, M., Long, R.E. et al. (1996) Inhibition of superantigen-induced proinflammatory cytokine production and inflammatory arthritis in MRL-lpr/lpr mice by a transcriptional inhibitor of TNF-a. $\mathcal{F}$ Immunol 157: 1758-1772.

Fairhurst, A.M., Mathian, A., Connolly, J.E., Wang, A., Gray, H.F., George, T.A. et al. (2008) Systemic IFN-alpha drives kidney nephritis in B6.Sle123 mice. Eur F Immunol 38: 1948-1960.

Fernandez, D., Bonilla, E., Mirza, N., Niland, B. and Perlet, A. (2006) Rapamycin reduces disease activity and normalizes $\mathrm{T}$ cell activation-induced calcium fluxing in patients with systemic lupus erythematosus. Arthritis Rheum 54: 2983-2988.

Furie, R., Looney, R.J., Rovin, B., Latinis, Kevin M., Appel, G., Sanchez-Guerrero, J., et al. (2009) Efficacy and safety of rituximab in subjects with active proliferative lupus nephritis: results from the randomized, double-blind phase III LUNAR study. Arthritis Rheum 60(suppl 1): S429. Abstract 1149.

Genovese, M.C., Van den Bosch, F., Roberson, S.A., Bojin, S., Biagini, I.M., Ryan, P. et al. (2010) 
LY2439821, a humanized anti-interleukin-17 monoclonal antibody, in the treatment of patients with rheumatoid arthritis: A phase I randomized, doubleblind, placebo-controlled, proof-of-concept study. Arthritis Rheum 62: 929-939.

Haas, C., Ryffel, B. and Le Hir, M. (1998) IFN- $\gamma$ receptor deletion prevents autoantibody production and glomerulonephritis in lupus-prone (NZB x NZW)F1 mice. F Immunol 160: 3713-3718.

Hahn, B.H. (2011) Targeted therapies in systemic lupus erythematosus: successes, failures and future. Ann Rheum Dis 70(Suppl. 1): i64-i66.

Harigai, M., Kawamoto, M., Hara, M., Kubota, T., Kamatani, N. and Miyasaka, N. (2008) Excessive production of IFN-gamma in patients with systemic lupus erythematosus and its contribution to induction of B lymphocyte stimulator/B cell-activating factor/ TNF ligand superfamily-13B. F Immunol 181: 2211-2219.

Houssiau, F.A., Lefebvre, C., Vanden Berghe, M., Lambert, M., Devogelaer, J.P. and Renauld, J.C. (1995) Serum interleukin 10 titers in systemic lupus erythematosus reflect disease activity. Lupus 4: 393-395.

Hueber, W., Patel, D.D., Dryja, T., Wright, A.M., Koroleva, I., Bruin, G. et al. (2010) Effects of AIN457, a fully human antibody to interleukin-17A, on psoriasis, rheumatoid arthritis, and uveitis. Sci Transl Med 6(2, 52): 52-72.

Illei, G.G., Shirota, Y., Yarboro, C.H., Daruwalla, J., Tackey, E., Takada, K. et al. (2010) Tocilizumab in systemic lupus erythematosus: data on safety, preliminary efficacy, and impact on circulating plasma cells from an open-label phase I dosage-escalation study. Arthritis Rheum 62: 542-552.

Ishida, H., Muchamuel, T., Sakaguchi, S., Andrade, S., Menon, S. and Howard, M. (1994) Continuous administration of anti-interleukin 10 antibody delays onset of autoimmunity in NZB/W F1 mice. $\mathcal{F}$ Exp Med 179: 305-310.

Iwai, H., Abe, M., Hirose, S., Tsushima, F., Tezuka, K., Akiba, H. et al. (2003) Involvement of inducible costimulator-B7 homologous protein costimulatory pathway in murine lupus nephritis. F Immunol 171: 2848-2854.

Jacobi, A.M., Odendahl, M., Reiter, K., Bruns, A., Burmester, G.R., Radbruch, A. et al. (2003) Correlation between circulating CD27 high plasma cells and disease activity in patients with systemic lupus erythematosus. Arthritis Rheum 48: 1332-1342.

Kalunian, K.C., Davis, J.C., Merrill, J.T., Totoritis, M.C. and Wofsy, D. (2002) Treatment of systemic lupus erythematosus by inhibition of $\mathrm{T}$ cell costimulation with anti-CD154: a randomized, double-blind, placebo-controlled trial. Arthritis Rheum 46: 3251-3258.

Kawamoto, M., Harigai, M., Masako Hara, M., Kawaguchi, Y., Tezuka, K., Tanaka, M. et al. (2006)
Expression and function of inducible co-stimulator in patients with systemic lupus erythematosus: possible involvement in excessive interferon- $\gamma$ and anti-doublestranded DNA antibody production. Arthritis Res Ther 8: R62.

Kawamura, M., McVicar, D.W., Johnston, J.A., Blake, T.B., Chen, Y.Q., Lal, B.K. et al. (1994) Molecular cloning of L-JAK, a Janus family protein-tyrosine kinase expressed in natural killer cells and activated leukocytes. Proc Natl Acad Sci U S A 91: 6374-6378.

Kremer, J.M., Bloom, B.J., Breedveld, F.C., Coombs, J.H., Fletcher, M.P., Gruben, D. et al. (2009) The Safety and Efficacy of a JAK Inhibitor in patients with active rheumatoid arthritis: results of a double-blind, placebo-controlled phase IIa trial of three dosage levels of CP-690,550 versus placebo. Arthritis Rheum 60: 1895-1905.

Kremer, J.M., Westhovens, R., Leon, M., Di Giorgio, E., Alten, R., Steinfeld, S. et al. (2003) Treatment of rheumatoid arthritis by selective inhibition of T-cell activation with fusion protein CTLA4Ig. $\mathrm{N} \mathrm{Engl} \mathcal{F} \mathrm{Med}$ 349: 1907-1915.

Krishnan, S., Juang, Y.T., Chowdhury, B., Magilavy, A., Fisher, C.U., Nguyen, H. et al. (2008) Differential expression and molecular associations of Syk in systemic lupus erythematosus $\mathrm{T}$ cells. $\mathcal{F}$ Immunol 181: 8145-8152.

La Cava, A. (2010) Targeting B cells with biologics in systemic lupus erythematosus. Expert Opin Biol Ther 10: 1555-1561.

Lawson, B.R., Prud'homme, G.J., Chang, Y., Gardner, H.A., Kuan, J., Kono, D.H. et al. (2000) Treatment of murine lupus with cDNA encoding IFN- $\gamma$ R/Fc. F Clin Invest 106: 207-215.

Leombruno, J.P., Einarson, T.R. and Keystone, E.C. (2009) The safety of anti-tumour necrosis factor treatments in rheumatoid arthritis: meta and exposureadjusted pooled analyses of serious adverse events. Ann Rheum Dis 68: 1136-1145.

Liang, B., Gardner, D.B., Griswold, D.E., Bugelski, P.J. and Song, X.Y. (2006) Anti-interleukin-6 monoclonal antibody inhibits autoimmune responses in a murine model of systemic lupus erythematosus. Immunology 119: 296-305.

Llorente, L., Richaud-Patin, Y., Garcia-Padilla, C., Claret, E., Jakez-Ocampo, J. and Cardiel, M.H. (2000) Clinical and biologic effects of anti-interleukin-10 monoclonal antibody administration in systemic lupus erythematosus. Arthritis Rheum 43: 1790-1800.

Matsumura, R., Umemiya, K., Sugiyama, T., Sueishi, M., Umibe, T., Ichikawa, K. et al. (2009) Anti-tumor necrosis factor therapy in patients with difficultto-treat lupus nephritis: a prospective series of nine patients. Clin Exp Rheumatol 27: 416-421.

McAdam, A.J., Chang, T.T., Lumelsky, A.E., Greenfield, E.A., Boussiotis, V.A., Duke-Cohan, J.S. et al. (2000) Mouse inducible costimulatory molecule 
(ICOS) expression is enhanced by CD28 costimulation and regulates differentiation of CD4+ $\mathrm{T}$ cells. F Immunol 165: 5035-5040.

Merrill, J.T., Buyon, J.P., Furie, R.A., Latinis, K.M., Gordon, C., Hsieh, H.J. et al. (2011) Assessment of flares in lupus patients enrolled in a phase II/III study of rituximab (EXPLORER). Lupus, [ePub ahead of print].

Mihara, M., Tan, I., Chuzhin, Y., Reddy, B., Budhai, L., Holzer, A. et al. (2000) CTLA4Ig inhibits T celldependent B-cell maturation in murine systemic lupus erythematosus. $\mathcal{F}$ Clin Invest 106: 91-101.

Morrow, T. (2011) FDA to act on benlysta, rare new drug for lupus. Manag Care 20: 43-44.

Nurieva, R.I., Treuting, P., Duong, J., Flavell, R.A. and Dong, C. (2003) Inducible costimulator is essential for collagen-induced arthritis. F Clin Invest 111: 701-706.

Ota, M., Duong, B.H., Torkamani, A., Doyle, C.M., Gavin, A.L., Ota, T. et al. (2010) Regulation of the B cell receptor repertoire and self-reactivity by BAFF. f Immunol 185: 4128-4136.

Perl, A., Fernandez, D.R., Telarico, T., Doherty, E., Francis, L. and Phillips, P.E. (2009) T-cell and B-cell signaling biomarkers and treatment targets in lupus. Curr Opin Rheumatol 21: 454-464.

Rönnblom, L., Alm, G.V. and Eloranta, M.L. (2009) Type I interferon and lupus. Curr Opin Rheumatol 21: 471-477.

Rottman, J.B., Smith, T., Tonra, J.R., Ganley, K., Bloom, T., Silva, R. et al. (2001) The costimulatory molecule ICOS plays an important role in the immunopathogenesis of EAE. Nat Immunol 2: 605-611.

Ryffel, B., Car, B.D., Gunn, H., Roman, D., Hiestand, P. and Mihatsch, M.J. (1994) Interleukin-6 exacerbates glomerulonephritis in (NZB NZW)F1 mice. Am $\mathcal{F}$ Pathol 144: 927-937.

Santiago-Raber, M.L., Baccala, R., Haraldsson, K.M., Choubey, D., Stewart, T.A., Kono, D.H. et al. (2003) Type-I interferon receptor deficiency reduces lupuslike disease in NZB mice. $\mathcal{F} \operatorname{Exp}$ Med 197: 777-788.

Soforo, E., Baumgartner, M., Francis, L., Allam, F., Phillips, P.E. and Perl, A. (2010) Induction of systemic lupus erythematosus with tumor necrosis factor blockers. F Rheumatol 37: 204-220.

Straub, R.H., Harle, P., Yamana, S., Matsuda, T., Takasugi, K., Kishimoto, T. et al. (2006) Anti-interleukin-6 receptor antibody therapy favors adrenal androgen secretion in patients with rheumatoid arthritis: a randomized, double-blind, placebo-controlled study. Arthritis Rheum 54: 1778-1785.

Suzuki, H., Yasukawa, K., Saito, T., Narazaki, M., Hasegawa, A., Taga, T. et al. (1993) Serum soluble interleukin-6 receptor in MRL/lpr mice is elevated with age and mediates the interleukin- 6 signal. Eur F Immunol 23: 1078-1082.
Theofilopoulos, A.N. and Lawson, B.R. (1999)

Tumour necrosis factor and other cytokines in murine lupus. Ann Rheum Dis 58(Suppl. 1): I49-I55.

Tsai, C.Y., Wu, T.H., Yu, C.L., Lu, J.Y. and Tsai, Y.Y. (2000) Increased excretions of $\beta$-microglobulin, IL-6, and IL- 8 and decreased excretion of Tamm-Horsfall glycoprotein in urine of patients with active lupus nephritis. Nephron 85: 207-214.

Uhm, W.S., Na, K., Song, G.W., Jung, S.S., Lee, T., Park, M.H. et al. (2003) Cytokine balance in kidney tissue from lupus nephritis patients. Rheumatology 42: 935-938.

Uppal, S.S., Hayat, S.J. and Raghupathy, R. (2009) Efficacy and safety of infliximab in active SLE: a pilot study. Lupus 18: 690-697.

Vadacca, M., Margiotta, D., Sambataro, D., Buzzulini, F., Lo Vullo, M., Rigon, A. et al. (2010) BAFF/APRIL pathway in Sjögren syndrome and systemic lupus erythematosus: relationship with chronic inflammation and disease activity. Reumatismo 62: 259-265.

Wallace, D.J., Petri, M., Olsen, N., Kirou, K., Dennis, G., Yao, Y. et al. (2007) MEDI-545, an anti-interferon alpha monoclonal antibody, shows evidence of clinical activity in systemic lupus erythematosus. Arthritis Rheum 56: S526-S527.

Wallace, D., Kalunian, K., Petri, M., Strand, V., Kilgallen, B., Barry, A., et al. (2010) Epratuzumab demonstrates clinically meaningful improvements in patients with moderate to severe systemic lupus erythematosus: results from EMBLEMTM, a phase IIb study. Ann Rheum Dis 69(suppl 3): 558. Abstract SAT0212.

Wang, X., Huang, W., Schiffer, L.E., Mihara, M., Akkerman, A., Hiromatsu, K. et al. (2003) Effects of anti-CD154 treatment on B cells in murine systemic lupus erythematosus. Arthritis Rheum 48: 495-506.

Weinblatt, M.E., Kavanaugh, A., Burgos-Vargas, R., Dikranian, A.H., Medrano-Ramirez, G., MoralesTorres, J.L. et al. (2008) Treatment of rheumatoid arthritis with a Syk kinase inhibitor: a twelve-week, randomized, placebo-controlled trial. Arthritis Rheum 58: 3309-3318.

Wiglesworth, A.K., Ennis, K.M. and Kockler, D.R. (2010) Belimumab: a BLyS-specific inhibitor for systemic lupus erythematosus. Ann Pharmacother 44: 1955-1961.

Wiley, R.E., Goncharova, S., Shea, T., Johnson, J.R., Coyle, A.J. and Jordana, M. (2003) Evaluation of inducible costimulator/B7-related protein-1 as a therapeutic target in a murine model of allergic airway inflammation. Am f Respir Cell Mol Biol 28: 722-730.

Wong, C.K., Lit, L.C., Tam, L.S., Li, E.K., Wong, P.T. and Lam, C.W. (2008) Hyperproduction of IL-23 and IL-17 in patients with systemic lupus erythematosus: implications for Th17-mediated inflammation in auto-immunity. Clin Immunol 127: 385-393.

Yao, Y., Richman, L., Higgs, B.W., Morehouse, C.A., de los Reyes, M., Brohawn, P. et al. (2009) 
Visit SAGE journals online http://tab.sagepub.com

QSAGEJOURNALS

Online
Neutralization of interferon-alpha/beta-inducible genes and downstream effect in a phase I trial of an antiinterferon-alpha monoclonal antibody in systemic lupus erythematosus. Arthritis Rheum 60: 1785-1796.

Yin, Z., Bahtiyar, G., Zhang, N., Liu, L., Zhu, P., Robertet, M.E. et al. (2002) IL-10 regulates murine lupus. F Immunol 169: 2148-2155.
Yoo, D.-H. (2010) Anticytokine therapy in systemic lupus erythematosus. Lupus 19: 1460-1467.

Yoshinaga, S.K., Zhang, M., Pistillo, J., Horan, T., Khare, S.D., Miner, K. et al. (2000) Characterization of a new human B7-related protein: B7RP-1 is the ligand to the co-stimulatory protein ICOS. Int Immunol 12: 1439-1447. 